\title{
DINÂMICA POPULACIONAL E FECUNDIDADE EM SUNAMPHITOE PELAGICA (H. MILNE EDWARS, 1830) E CYMDUSA FILOSA SAVIGNY, 1816 ASSOCIADOS A SARGASSUM SP. EM UMA ENSEADA COM INFLUÊNCIA ANTRÓPICA
}

\author{
Longo, P.A.S. ${ }^{1,}$; Olivino, A.L.L. ${ }^{1}$; Vicente, V.S. ${ }^{1}$; Mansur, K.F.R. ${ }^{1}$ \& Leite, F.P.P. ${ }^{1}$ \\ ${ }^{1}$ Universidade Estadual de Campinas (UNICAMP), Campus Campinas, \\ Laboratório de Interações entre Comunidades Marinhas. \\ *Autor correspondente: pedro.slongo@gmail.com
}

\begin{abstract}
O Saco da Ribeira, localizado na Enseada do Flamengo, Ubatuba, Litoral Norte de São Paulo, é uma região com posição geográfica privilegiada, com proteção do embate direto das ondas, favorecendo a concentração de estabelecimentos voltados para o turismo e atividade náutica, entre eles, uma marina estadual. Devido à grande influência antrópica, esta região vem sendo apontada como contaminada por hidrocarbonetos e metais pesados por relatórios da Companhia Ambiental do Estado de São Paulo (CETESB). Assim, o presente estudo teve como objetivo estudar a dinâmica populacional e as variações nos parâmetros de fecundidade em populações dos anfípodes herbívoros Cymadusa filosa e Sunamphitoe pelagica associados a Sargassum sp. na Enseada do Flamengo. Para tanto, amostras de Sargassum sp. foram coletadas em dois anos consecutivos no período de inverno e verão em quatro pontos: dois localizados próximos ao Saco da Ribeira, considerado o principal foco de poluição (Lamberto: $23^{\circ} 29^{\prime} 46.2^{\prime \prime} \mathrm{S} 45^{\circ} 06^{\prime} 41.8^{\prime \prime} \mathrm{O}$; Ribeira: $23^{\circ} 30^{\prime} 18.4^{\prime \prime} \mathrm{S} 45^{\circ} 07^{\prime} 08.6^{\prime \prime} \mathrm{O}$ ); e outros dois

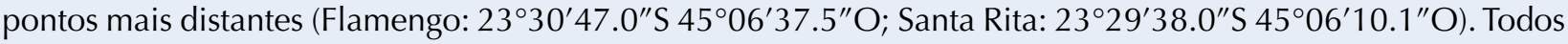
os indivíduos de C. filosa e $S$. pelagica foram medidos e agrupados em classes de tamanho, e as fêmeas ovígeras encontradas tiveram os seus ovos contados e medidos para análise do número de ovos por fêmea e volume dos ovos, utilizados como parâmetros de fecundidade. As amostras de algas foram secas em estufa a $70^{\circ} \mathrm{C}$ por $48 \mathrm{~h}$ para obtenção da biomassa seca. As abundâncias de S. pelagica e C. filosa foram relacionadas positivamente com a biomassa de Sargassum sp.. As densidades de ambas espécies de anfípodes apresentaram diferenças apenas em relação às estações, sendo maiores no verão (ANOVA, S. pelagica: $p=0,0002$; $C$ filosa: $p=0,0007$ ) . As populações das duas espécies foram representadas majoritariamente por jovens, mostrando que a alga além de ser utilizada como recurso alimentar é também um sítio reprodutivo. A razão sexual para as duas espécies estudadas foi voltada para as fêmeas (S. pelagica - $0,15: 1$; C. filosa - $0,14: 1$ ) e o número de ovos por fêmea não variou entre os pontos. Somado a isso, o número e volume dos ovos de $S$. pelagica e C. filosa apresentaram valores reduzidos quando comparados a estudos realizados em outras localidades, levantando-se a hipótese de que a Enseada do Flamengo como um todo pode estar sendo afetada pelo aporte de contaminantes e impactos antrópicos.
\end{abstract}

Palavras-chave: Ampithoidae, macroalgas, Ubatuba. 